set up, as some have done, the petty irregularities of limited data, as so many declared laws of nature, when, by the very amalgamation of the elements of such data, or by their extension, a simple law of increase is the only one fairly observable.

By adopting, then, this law of increase at great intervals, as a type of what might be expected for lesser intervals, were more extensive experience at hand, we not only protect ourselves from paradoxical triflings, bnt walk in the steps pointed out by the doctrine of probability itself: for if a series of increasing ratios at wide intervals be presented to us, the most probable interpolations, among the infinity of all the possible ones, are those of a cognate character with the general type of the declared series; and it is to detect what this general type is, that all mathematical formulæ essentially tend. Individnally, I should be sorry to rob any healthy senior of the solace be may find in thinking he has an equal chance of surviving to his next birthday as his juniors; but, as an actuary, I consider it is merely attempting to sustain an obsolete paradox to pretend, that such is to be taken as the general attribate, displayed to us by a sufficient experience.

In conclusion, I may be allowed to state, that I have not been content to allow Mr. Spens' paper to pass unnoticed (as I might, I conceive, very safely have done, so far as the argument is concerned), but have rather replied to it at full length, not only as an act of courtesy to that gentleman, whom I personally respect, but also because I feel convinced that, however actuaries may differ in opinion, yet that free and open discussion, without ill feeling and withont personal imputations, forms one of the surest indications that the public can possess, that the subject of insurance, in which they all have so deep an interest, is being at once honestly and efficiently studied.

Your obedient Servant,

London, Sept. 1, $1853 . \quad$ EDWIN JAMES FARREN.

\title{
ON THE VALUES OF REVERSIONS PAYABLE AT THE INSTANT OF DEATH.
}

To the Editor of the Assurance Magazine.

Sis,-I beg to thank you for correcting the errors in my letter published in last Magazine, and, through you, to apologize to your readers for the obseurity which they necessarily occasioned in the meaning. I hope yon will also allow me this opportunity to extend my observations a little on the subject, lest I should not have been sufficiently understood.

The determination of the valne of reversions payable at the instant of death may not on first view seem to be an inquiry of much practical atility, since it has never been the practice, so far as I know, to pay claims immediately after proof of death; but the fact that some Offices now do pay claims within a few weeks thereafter, renders a decision on the point the more urgent, and the inquiry more inviting to the actuary, irrespective of the interest which usually accompanies investigations of this kind.

It appears to me, that since one year has naturally become the unit for measuring the decrements of human life as well as the improvement of money, the practice has arisen, in life calculations, of assuming the reversion to be payable at the end of the year in which death occurs, when the conversion of interest takes place, the same being then dne-or, in other words, 
six months after death; though many Offices have been in the habit of paying claims much earlier. And this circumstance may have led Mr. Sang in his computations to assume it as a fixed principle that money was to yield no more than a given rate per cent. per annum of interest; and that consequently, since the claim was to be paid as soon as death happened, or six months from the date of the last conversion of interest, it became necessary that the last six months' interest, being the interest for the first half of the last year, should be discounted for six months, the same not being due till the end of that year. On this assumption, the discounting of the interest seems to be quite reasonable, in consideration of the advantage which the representative would derive from its improvement until the end of the year; and the assured is therefore entitled to pay a higher premium. If this principle be correct, then Mr. Sang's method of computing the valne of the reversion payable at the instront of death is in strict accordance therewith, and sufficiently justifies and explains the introdnction of the quantity $\sqrt{1+i}$ into his tables.

Being of opinion that this view is one which can be legitimately maintained, it is unfair in me to characterize his tables as erroneous; and thongh the opinion expressed in my last communication must be somewhat modified, I cannot think that his principle is the most equitable. I hold it to be more correct in theory, as well as more equitable, to assume the interest to be dne when the claim is due-that is, in the middle of the year; and therefore that a fill half year's interest should be paid for the last half year, from the date of the last conversion of interest, at the beginning of the year, to the date of death. The effect of this, of course, will be to diminish slightly the value of the reversion; for while the increased liability on account of interest is admitted, and therefore to be provided for in computing the value, no higher sum than $£ 1$ must be assured to be paid.

The value under such conditions is, I think, correctly shown by $\mathrm{Mr}$. Farren to be $\frac{1-i \mathrm{~A}}{1+\frac{i}{2}}$, which may be adapted to suit Mr. Sang's method of computing by writing it thas (corrected)-

$$
\frac{1+i}{1+\frac{i}{2}} \times\left(\frac{v d_{x}+v^{2} d_{\overline{z+1}}+v^{3} d_{\overline{x+2}}+\& e_{2}}{l_{x}}\right) \ldots \ldots \ldots(a)
$$

while Mr. Sang's expression for the valne-correctly stated, and keeping in view that $\sqrt{1+i}=\frac{1+i}{\sqrt{1+i}}$, is

$$
\frac{1+i}{\sqrt{1+i}} \times\left(\frac{v d_{x}+v^{2} d_{x+1}+v^{3} d_{x+2}+\& c .}{l_{x}}\right) \ldots \ldots \ldots(b) .
$$

It will be observable that these two expressions differ only from one another in the value of their coefficients; the one being to the other as $\sqrt{1+i}$ to $1+\frac{i}{2}$, which, at 3 per cent. interest, will be found to be as 1 to

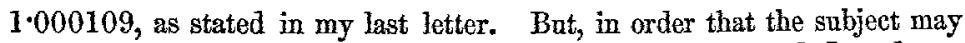
be practically illustrated, and the results thoroughly compared, I send you two sets of tables for insertion, if you can spare room, both having been 
computed on the columnar system; whereof Tables I. and II. are based on formula (a), and Tables III. and IV. are copies of Mr. Sang's original tables, and are of course based on formula $(b) . *$

I considered it nnnecessary to occupy your space with the $D$ and $N$ columns in connection with Tables I. and III., since these can be so easily referred to in Jones, pages 291 and 292.

I have only in conclusion to suggest, that it will afford much gratification, to any person who will take the trouble, to verify the values of the reversion as given in Table II., by Mr. Farren's formula; but, in order to insure a close and satisfactory approximation, the annuity should be taken from Gray's Assurance and Annuity Tables, or from Thomson's Actuarial Tables, where the value of $\mathrm{A}$ is given to five decimal places. Mr. Sang's reversion may also be verified in a similar manner, by dividing by $\sqrt{1+i}$.

\section{DAVID CHISHOLM.}

\section{North British Insurance Office, Edinburgh.}

\section{THE INTEREST QUESTION.}

\section{To the Editor of the Assurance Magazine.}

Sir,-In your last Number, a Mr. Filipowski asks a well known writer how he would, according to his own plan, solve the following problem: $s=$ sum; $d=$ rate of interest; $a=$ amount; $x=$ period or daration. In what time will the sum $s$ amount to $a$, at compound interest? As it is not to be expected that the writer referred to will formally reply to so simple a question, perhaps, as a young Associate of the Institute of Actnaries, I may be allowed to point ont to $\mathrm{Mr}$ Filipowski, who appears from his name and style to be a foreigner, that all our Finglish elementary treatises on algebra tonch on compond interest, and demonstrate that, if $s(1+d)^{*}$ is to equal $a$, that $x$, as a period or duration, will equal the logarithm of $a$ divided by the logarithm of $s(1+d)$. I may also direct Mr. Filipowski's attention to a work published in 1816, entitled Investigation of the Errors of all Writers on Annuities, in their valuation of half yearly and quarterly payments, \&c., \&c.; by Wm. Ronse. Mr. Ronse, like Mr. Filipowski, takes up the old notion of D'Alembert, embodied by Mr. Smart in his tables, of nsing the geometrical mean of $(1+d)^{\frac{1}{2}}$ between 1 and $(1+d)$, instead of the arithmetical mean of $\left(1+\frac{d}{2}\right)$, as in common use; but as the notions expressed by the two cases are very different in theory, $\mathrm{Mr}$. Corbanx has pointedly said, in his Doctrine of Compound Interest, p. 64, "This writer has taken great pains merely to prove truisms." Accordingly, all the best modern interest tables, like those of Mr. Peter Hardy and Mr. Rance, are framed for half yearly and quarterly interest on the same formule as those of Corbanx, and not npon the antiquated ones of D'Alembert and Smart, so severely criticised by Mr. Milne and the writer in the Penny Cyclopadia.

\section{Yours respectfally,}

\section{A YOUNG ASSOCIATE.}

* See "Original Tables," pp. 89-92. 